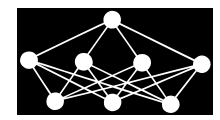

\title{
APPLICATION OF A PROBABILISTIC NEURAL NETWORK FOR LIQUEFACTION ASSESSMENT
}

\author{
X. Xue, X. Yang*, P. $L i^{\dagger}$
}

\begin{abstract}
This paper presents a hybrid probabilistic neural network (PNN) and particle swarm optimization (PSO) techniques to predict the soil liquefaction. The PSO algorithm is employed in selecting the optimal smoothing parameter of the PNN to improve the forecasting accuracy. Seven parameters such as earthquake magnitude, normalized peak horizontal acceleration at ground surface, standard penetration number, penetration resistance, relative compaction, mean grain diameter and groundwater table are selected as the evaluating indices. The predictions from the PSO-PNN model were compared with those from two models: backpropagation neural network (BPNN) model and support vector machine (SVM) model. The study concluded that the proposed PSO-PNN model can be used as a reliable approach for predicting soil liquefaction.
\end{abstract}

Key words: earthquake, soil liquefaction, probabilistic neural network, particle swarm optimization

Received: August 6, 2015

DOI: $10.14311 / \mathrm{NNW} .2017 .27 .030$

Revised and accepted: October 25, 2017

\section{Introduction}

Liquefaction is defined as the transformation of a granular material from a solid to a liquefied state as a consequence of increased pore-water pressure and reduced effective stress [13]. During the liquefaction, pore water pressure exerts a pressure on the soil particles that influences how tightly the particles themselves are pressed together. Prior to an earthquake, the water pressure is relatively low. However, earthquake shaking can cause the water pressure to increase to the point where the soil particles can readily move with respect to each other. The effective stress of the soil reduces, therefore, causing loss of bearing capacity $[18,19]$. It then is said that soil liquefaction has occurred. Liquefaction of saturated sandy soils has been considered as the main cause of most geotechnical hazards during earthquakes [3]. Examples of liquefaction hazards were observed in the historical earthquakes, such

\footnotetext{
*Xinhua Xue - Corresponding Author; Xingguo Yang; State Key Laboratory of Hydraulics and Mountain River Engineering, College of Water Resource and Hydropower, Sichuan University, Chengdu, Sichuan, 610065, P.R.China, E-mail: scuxxh@163.com, 89022251@163.com

${ }^{\dagger}$ Peng Li; Dadu River Hydropower Development Co., Ltd, Chengdu, Sichuan, 610041, P.R.China, E-mail: iroi.lee@163.com
} 
as the 1964 Niigata, the 1964 Alaska, the 1971 San Fernando, the 1976 Tangshan, the 1989 Loma Prieta, the 1995 Kobe, the 1999 Taiwan, the 2001 Bhuj, the 2008 Wenchuan, the 2011 Tōhoku, and the 2015 Nepal earthquakes. Therefore, the assessment of liquefaction potential due to an earthquake at a site is an imperative task in geotechnical earthquake engineering.

Although many of the existing assessment methods, such as standard penetration test (SPT) $[10,11,16,27]$ and the cone penetration test (CPT) $[8,9]$ were used for simple liquefaction assessment by many geotechnical engineers. However, all of the above methods are associated with some inherent uncertainties [20] and it is difficult to select a suitable empirical equation for regression analysis due to the high uncertainty in earthquake environments and soil characteristics [4].

In recent years there are several attempts to use intelligent computational systems such as artificial neural networks (ANNs) in geotechnical engineering. This growing interest among researchers is stemming from the fact that these learning machines have an excellent performance in the issues of pattern recognition and the modeling of non-linear relationships of multivariate dynamic systems. However, ANNs have several inherent drawbacks such as over-fitting, slow convergence, poor generalizing performance, arriving at local minimum [14]. To overcome these limitations, Specht $[22,23]$ introduced the probabilistic neural network (PNN). The learning time for the PNN is generally shorter than that for the multilayer feed-forward algorithm, as only one smoothing parameter requires adjustment or optimization. This paper investigates the potential of PNN for prediction of soil liquefaction. To improve the forecasting accuracy, the particle swarm optimization (PSO) algorithm was employed in obtaining the optimal smoothing parameter of the PNN in this study.

\section{Probabilistic neural network}

The PNN is basically a pattern classifier that combines the well-known Bayes decision strategy with the Parzen [15] nonparametric estimator of the probability density functions of different classes. Generally, the PNN structure consists of four layers: an input layer, a pattern layer, a summation layer, and an output layer. For illustration purposes, a simple PNN architecture comprising four layers is depicted in Fig. 1. The overview of the PNN is briefly described below.

Considering a pattern vector $\boldsymbol{x}$ with $m$ dimensions that belongs to one of two categories $K_{1}$ and $K_{2}$. According to the Bayes' decision rule, $\boldsymbol{x}$ belongs to $K_{1}$ if $[2,6]$

$$
\frac{F_{1}(x)}{F_{2}(x)}>\frac{L_{1} P_{2}}{L_{2} P_{1}}
$$

Conversely, $\boldsymbol{x}$ belongs to $K_{2}$ if

$$
\frac{F_{1}(x)}{F_{2}(x)}<\frac{L_{1} P_{2}}{L_{2} P_{1}}
$$

where $F_{1}(x)$ and $F_{2}(x)$ are the probability density functions for the classification categories $K_{1}$ and $K_{2}$, respectively. $L_{1}$ is the loss or cost function associated with misclassifying the vector as belonging to category $K_{1}$ while it belongs to category 
Xue X., Yang X., Li P.: Application of a probabilistic neural...

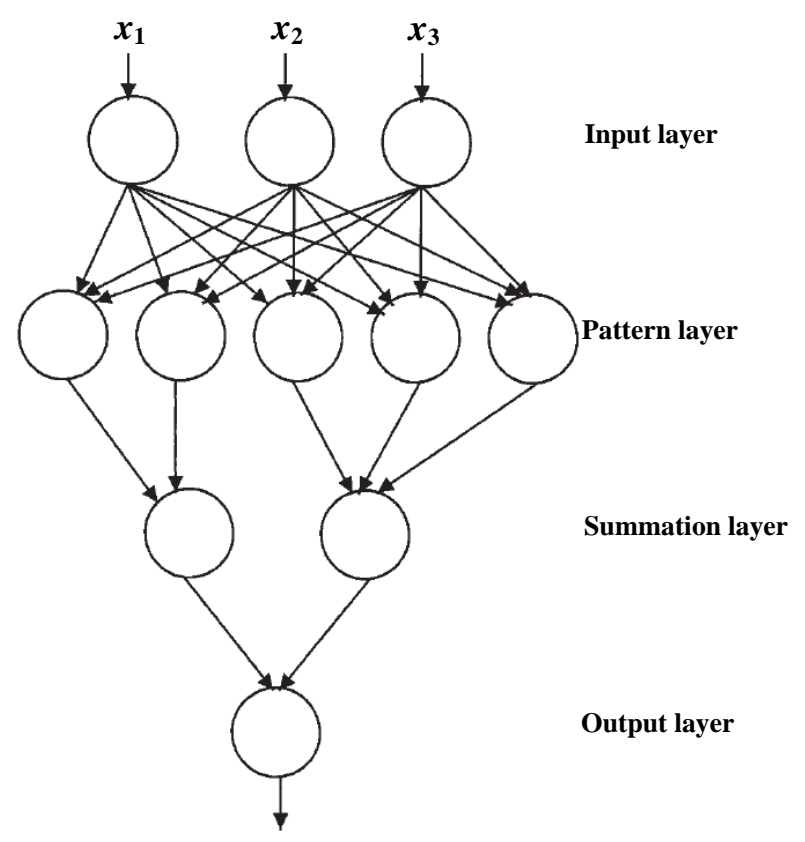

Fig. 1 The basic architecture of the PNN.

$K_{2}, L_{2}$ is the loss function associated with misclassifying the vector as belonging to category $K_{2}$ while it belongs to category $K_{1}, P_{1}$ and $P_{2}$ are the prior probability of occurrence of category $K_{1}$ and $K_{2}$, respectively.

If the $j$-th training pattern for category $K_{1}$ is $\boldsymbol{x}_{j}$, then the Parzen estimate of the probability density function for category $K_{1}$ can be expressed as $[6,7]$

$$
F_{1}(x)=\frac{1}{(2 \pi)^{\mathrm{m} / 2} \sigma^{m} n} \sum_{j=1}^{n} \exp \left[-\frac{\left(x-x_{j}\right)^{T}\left(x-x_{j}\right)}{2 \sigma^{2}}\right]
$$

where $n$ is the number of training patterns, $m$ is the input space dimension, $j$ is the pattern number, and $\sigma$ is an adjustable smoothing parameter.

\section{PNN optimized by PSO (PSO-PNN)}

PSO algorithm developed by Kennedy and Eberhart [12], is a population-based heuristic search technique inspired by social behavior of bird flocking and fish schooling $[5,17,24]$. In this approach, global optimums can be searched as well as local optimal solutions $[1,25,26]$. Let $t$ be a time instant the velocity and position of each particle are updated by Eqs. (4) and (5), respectively.

$$
\begin{gathered}
v_{i}^{t+1}=\kappa v_{i}^{t}+c_{1} r_{1}\left(P_{i}-x_{i}^{t}\right)+c_{2} r_{2}\left(P_{g}-x_{i}^{t}\right), \quad i=1,2, \cdots, N \\
x_{i}^{t+1}=x_{i}^{t}+v_{i}^{t+1}
\end{gathered}
$$


where $c_{1}$ and $c_{2}$ are the acceleration coefficients; $r_{1}$ and $r_{2}$ are two independent random numbers uniformly distributed in the range $[0,1] ; \kappa$ is the inertia weight. $P_{i}$ is the best previous position of the particle, while $P_{g}$ is the best position among all the particles in the swarm.

In this study, the PSO algorithm has been selected for optimization of the $\sigma$ value in the PNN classifier. It should be noted that the searching domain of the $\sigma$ parameter in this study has been restricted to the range $\sigma \in[0.1,5]$. Here, it is assumed that the chosen values can cover a range of the parameter search space, which leads to a high prediction accuracy. To evaluate the performance of the proposed PSO-PNN approach, the correct classification rate of samples is used as follows:

$$
\operatorname{Accuracy}(\%)=\frac{N_{\text {correct }}}{N} \times 100 \%
$$

where $N_{\text {correct }}$ is the number of correctly classified samples. $N$ is the total number of samples.

The implementation of the proposed PSO-PNN model was carried out using the MATLAB R2012b program in this study. The main steps of the proposed PSO-PNN approach are described below.

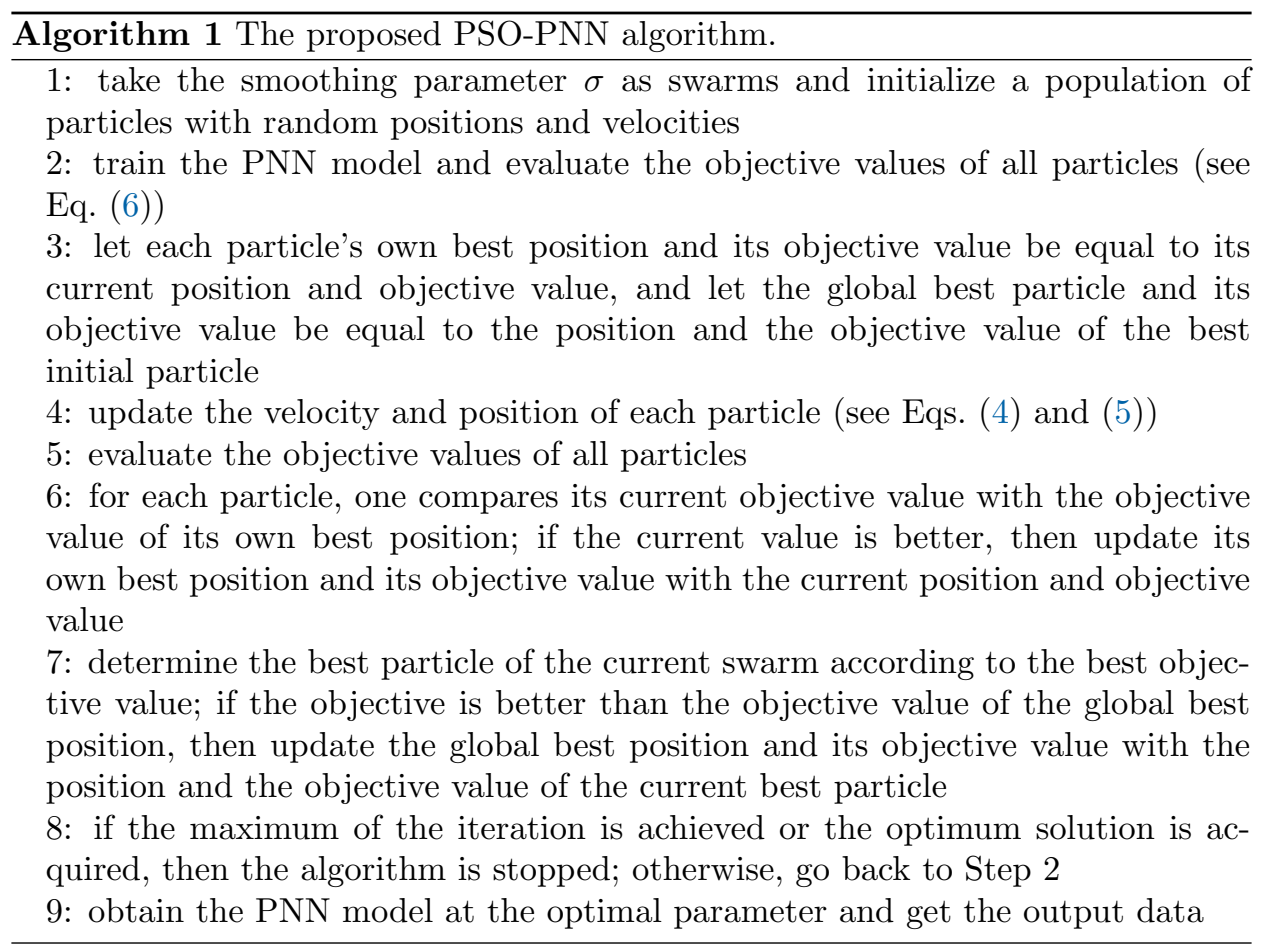

A flowchart of the proposed PSO-PNN algorithm is illustrated in Fig. 2. 
Xue X., Yang X., Li P.: Application of a probabilistic neural...

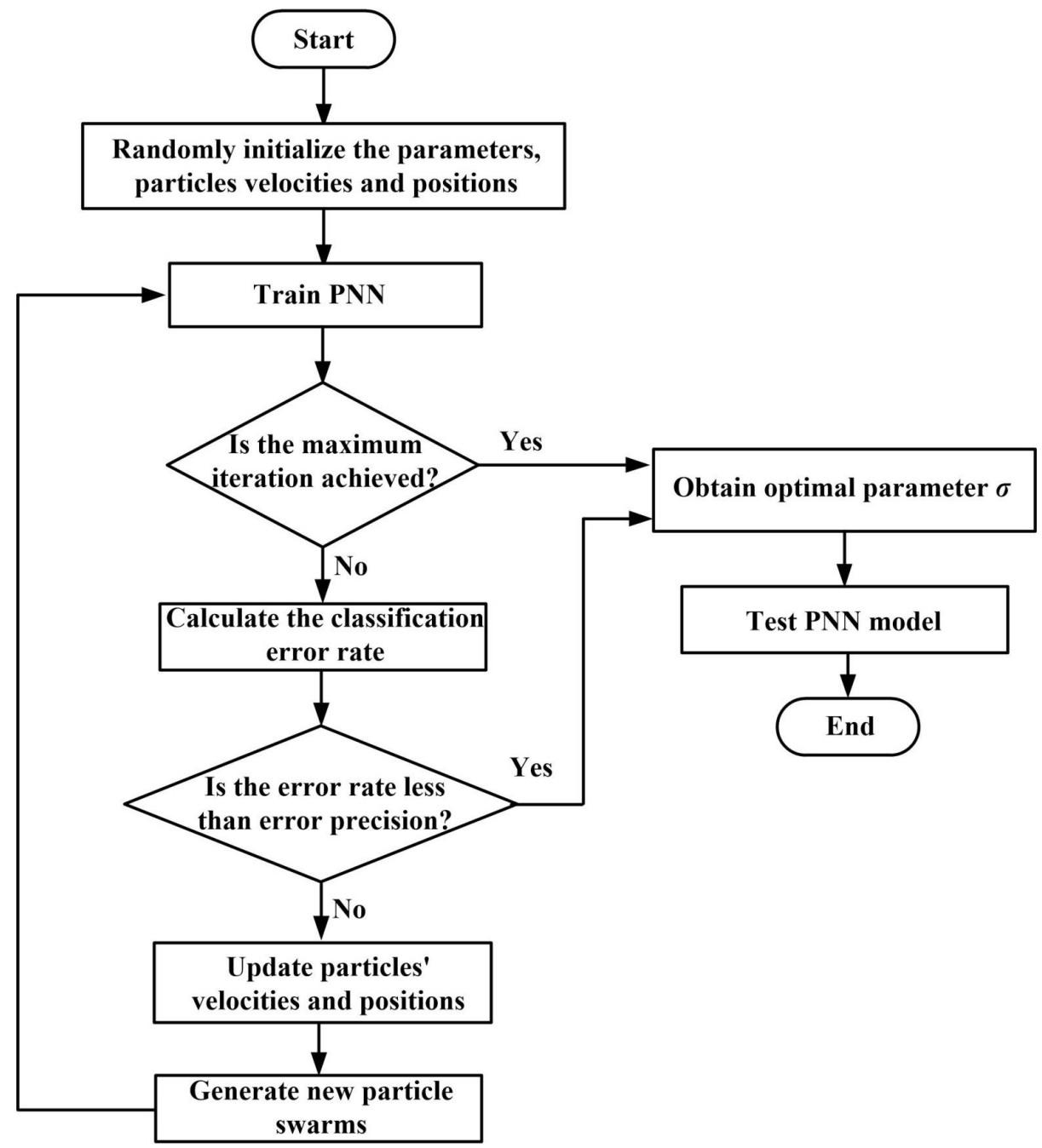

Fig. 2 Flowchart of the PSO-PNN algorithm.

\section{Case study}

Database It should be noted that the susceptibility of soil deposits to liquefaction is determined by a combination of various factors to which they may be subjected, such as soil properties, geological conditions and ground motion characteristics. Among the factors above, soil properties and geological conditions determine the resistance of the deposit to liquefaction, while earthquake characteristics control the seismic loading conditions [8]. Accordingly, the following factors are chosen as the evaluating indices: earthquake magnitude $(M)$, normalized peak horizontal acceleration at ground surface $\left(\alpha_{\max }\right)$, standard penetration number $\left(N_{63.5}\right)$, penetration resistance $\left(P_{s}\right)$, relative compaction $\left(D_{r}\right)$, mean grain diameter $\left(D_{50}\right)$ and 
groundwater table $\left(d_{w}\right)$, whereas the liquefaction grade is the output parameter. The database used in this study includes 24 field observations from the 1976 Tangshan earthquake and the 1997 Sanshui earthquake (Tab. I) [21]. Two thirds of the case records were selected for the training phase and the remaining one third for the testing phase. Liquefaction grade was divided into 4 grades: serious liquefaction, medium liquefaction, slight liquefaction and non-liquefaction (Tab. II) [21]. Again, for each case, "1" represents serious liquefaction, "2" represents medium liquefaction, "3" represents slight liquefaction and " 4 " denotes non-liquefaction.

\begin{tabular}{ccccccccc}
\hline No. & $M$ & $\alpha_{\max }(\mathrm{m} / \mathrm{s})$ & $N_{63.5}$ & $P_{s}(\mathrm{kPa})$ & $D_{r}$ & $D_{50}(\mathrm{~mm})$ & $d_{w}(\mathrm{~m})$ & $\begin{array}{c}\text { Liquefaction } \\
\text { grade }\end{array}$ \\
\hline 1 & 6.1 & 0.2 & 8 & 1.2 & 0.25 & 0.22 & 1.0 & 1 \\
2 & 5.8 & 0.25 & 11 & 2.31 & 0.3 & 0.18 & 1.5 & 1 \\
3 & 4.2 & 0.15 & 8 & 0.75 & 0.4 & 0.18 & 0.6 & 2 \\
4 & 6.4 & 0.2 & 36 & 17.30 & 0.85 & 0.1 & 2.5 & 4 \\
5 & 5.6 & 0.2 & 42 & 17.12 & 0.8 & 0.05 & 2.4 & 4 \\
6 & 2.3 & 0.1 & 15 & 9.18 & 0.3 & 0.3 & 1.6 & 3 \\
7 & 3.5 & 0.1 & 30 & 15.33 & 0.6 & 0.28 & 3.0 & 4 \\
8 & 4.7 & 0.15 & 7 & 0.94 & 0.2 & 0.07 & 0.8 & 1 \\
9 & 5.2 & 0.15 & 10 & 4.78 & 0.3 & 0.13 & 1.3 & 2 \\
10 & 5.0 & 0.1 & 46 & 17.32 & 0.7 & 0.04 & 2.0 & 4 \\
11 & 6.3 & 0.15 & 24 & 11.36 & 0.6 & 0.1 & 2.1 & 3 \\
12 & 7.3 & 0.2 & 17 & 9.57 & 0.55 & 0.17 & 3.2 & 3 \\
13 & 8.4 & 0.2 & 19 & 6.21 & 0.33 & 0.05 & 1.7 & 2 \\
14 & 7.6 & 0.25 & 15 & 7.8 & 0.4 & 0.12 & 0.9 & 2 \\
15 & 4.2 & 0.25 & 9 & 3.43 & 0.3 & 0.13 & 1.2 & 1 \\
16 & 4.2 & 0.05 & 19 & 9.82 & 0.65 & 0.04 & 1.1 & 3 \\
17 & 4.2 & 0.1 & 14 & 15.87 & 0.55 & 0.1 & 1.0 & 3 \\
18 & 4.2 & 0.1 & 11 & 4.85 & 0.35 & 0.2 & 1.8 & 2 \\
19 & 4.3 & 0.15 & 16 & 6.94 & 0.3 & 0.17 & 2.2 & 2 \\
20 & 6.1 & 0.2 & 8 & 3.45 & 0.25 & 0.15 & 1.0 & 1 \\
21 & 4.2 & 0.5 & 32 & 16.76 & 0.5 & 0.1 & 2.5 & 4 \\
22 & 4.2 & 0.5 & 39 & 15.41 & 0.65 & 0.09 & 2.2 & 4 \\
23 & 4.2 & 0.5 & 17 & 9.61 & 0.55 & 0.25 & 2.0 & 3 \\
24 & 4.2 & 0.1 & 13 & 5.62 & 0.5 & 0.03 & 1.2 & 3 \\
\hline & & & & & & & & \\
\hline
\end{tabular}

Tab. I Dataset used in case study (data from [21]).

Results and discussion As mentioned, the goal of the optimization process is to maximize the PNN accuracy value. In this study, the PSO parameters are given as follows: $n_{\max }=20$ (maximum iterations), $N_{p}=30$ (swarm size), $c_{1}=c_{2}=2.0$. The PNN smoothing parameter $\sigma=1.5$, presented in Fig. 3, has been obtained after the training and optimization process. The PNN Accuracy and PSO epoch has also been established on the basis of the same training set, as shown in Fig. 4. Fig. 5 shows the predicted results of training samples. As can be seen from Figs. 3, 
Xue X., Yang X., Li P.: Application of a probabilistic neural...

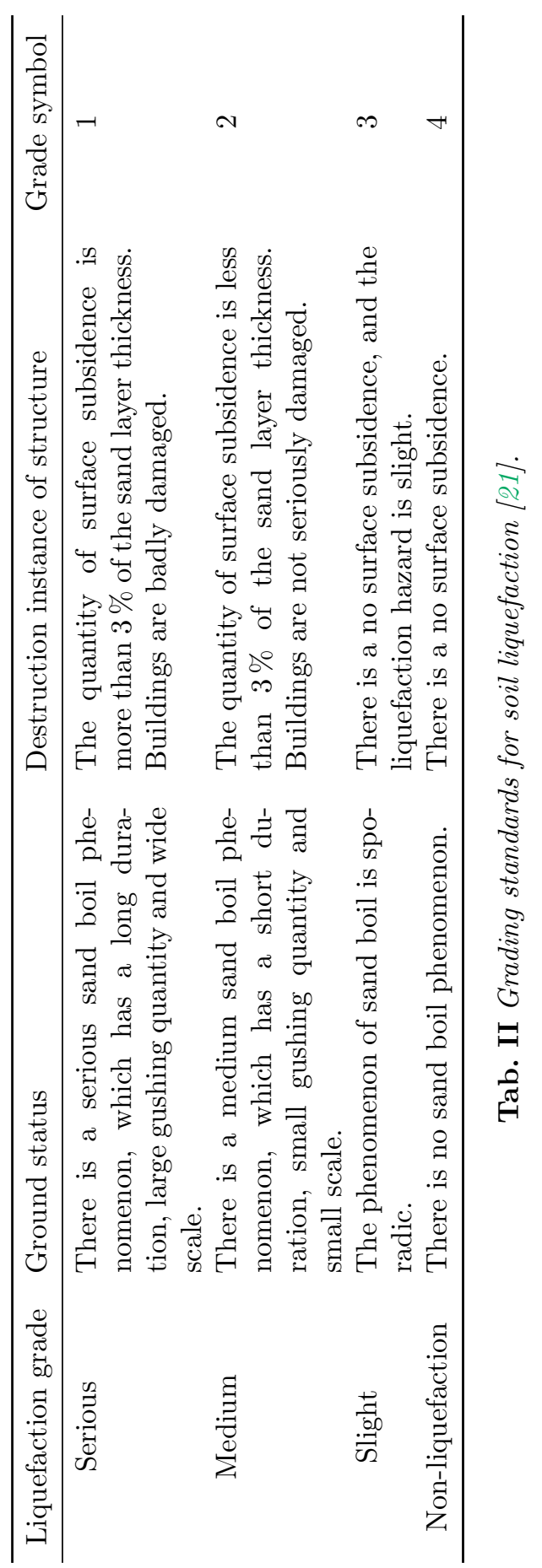


4 and 5 , the predictions using the PNN with $\sigma=1.5$ for the training data had a high success rate of $100 \%$. Therefore the model of the PNN classifier was completely built and used for the testing data.

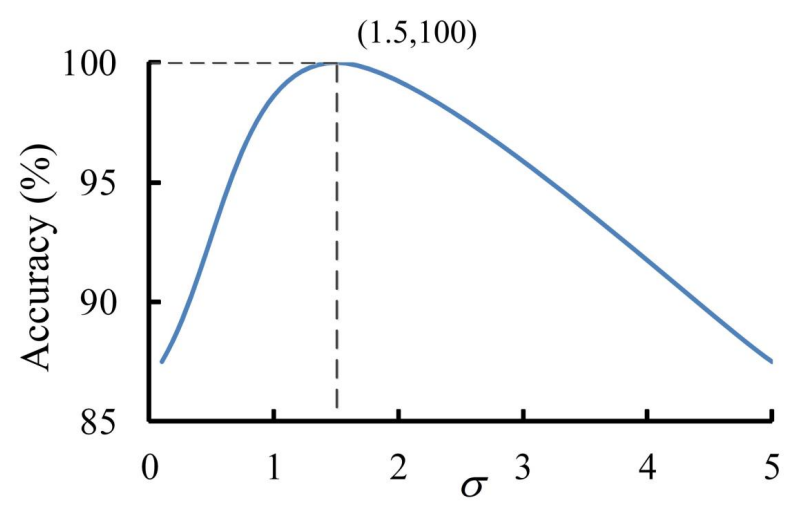

Fig. 3 Accuracy vs. smoothing parameter $\sigma$.

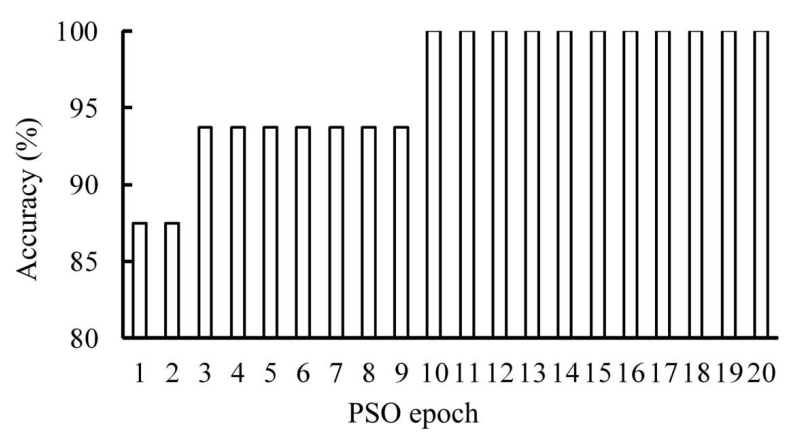

Fig. 4 Accuracy vs. PSO epoch.

To verify the effectiveness of the proposed PSO-PNN model, the predicted results are compared to those obtained by means of some other methods, such as back-propagation neural network (BPNN) model and support vector machine (SVM) model [21]. Tab. III shows a comparison of the three models for the prediction of soil liquefaction.

From Tab. III it can be seen that the predictions using the PNN with $\sigma=1.5$ for the testing data had an overall classification accuracy rate of $100 \%$. This represents a significant improvement over the BPNN method [21], which had 1 error or a success rate of $87.5 \%$ for the testing samples. Prediction results demonstrate that the PSO-PNN model can be used as a reliable approach for predicting soil liquefaction. Of course, it cannot be denied that the SVM model is also a powerful computational tool that can be used to assess the soil liquefaction potential. 
Xue X., Yang X., Li P.: Application of a probabilistic neural...

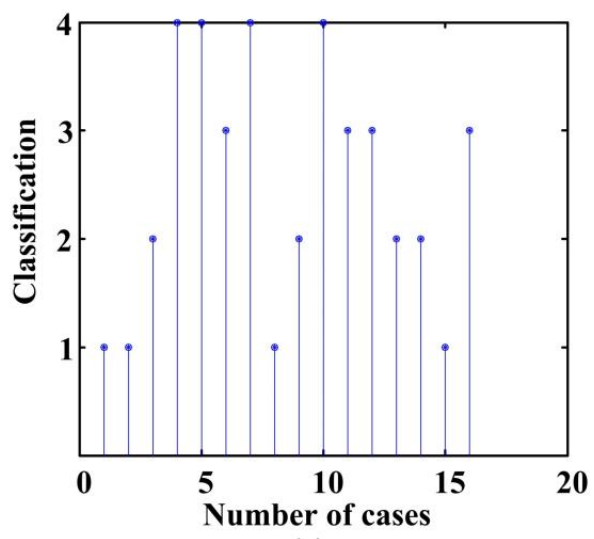

(a)

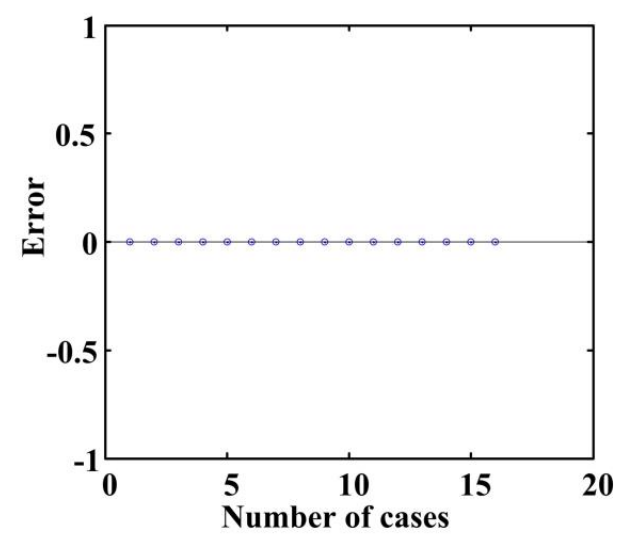

(b)

Fig. 5 Predicted results of training samples: (a) Classification; (b) Error.

\begin{tabular}{ccccc}
\hline No. & Liquefaction grade & PSO-PNN & BPNN & SVM \\
\hline 17 & 3 & 3 & 3 & 3 \\
18 & 2 & 2 & 2 & 2 \\
19 & 2 & 2 & 2 & 2 \\
20 & 1 & 1 & 1 & 1 \\
21 & 4 & 4 & 4 & 4 \\
22 & 4 & 4 & 4 & 4 \\
23 & 3 & 3 & 3 & 3 \\
24 & 3 & 3 & 2 & 3 \\
\hline
\end{tabular}

Tab. III Comparison between the forecasted and actual results.

\section{Conclusions}

Determination of liquefaction potential is a complex geotechnical engineering problem due to the heterogeneous nature of the soils and the participation of a large number of factors that affect the liquefaction occurrence due to earthquake. This study presents a hybrid PNN and PSO techniques to predict the soil liquefaction. PSO was employed in selecting the optimal smoothing parameter of PNN to enhance the forecasting accuracy. The results show that the PSO-PNN is a powerful computational tool that can be used to analyze the complex relationship between soil and seismic parameters in liquefaction assessment. Moreover, the results also indicate that the PSO-PNN achieves greater classification accuracy than BPNN model. Thus, PSO-PNN is a novel liquefaction assessment tool worthy of promotion and support. 


\section{Neural Network World 6/2017, 557-567}

\section{References}

[1] AFSHAR M.H., RAJABPOUR R. Application of local and global particle swarm optimization algorithms to optimal design and operation of irrigation pumping systems. Irrig Drain. 2009, 58, pp. 321-331, doi: 10.1002/ird.412.

[2] BOLAT B., YILDIRIM T. Performance increasing methods for probabilistic neural networks. Pakistan J Info Technol, 2003, 2(3), pp. 250-255, doi: 10.3923/itj.2003.250.255.

[3] BELKHATIR M., SCHANZ T., ARAB A., DELLA N., KADRI A. Insight into the effects of gradation on the pore pressure generation of sand-silt mixtures. Geotech Test J, 2014, 37(5), pp. 922-931, doi: 10.1520/GTJ20130051.

[4] CHERN S.G., LEE C.Y. CPT-based simplified liquefaction assessment by using fuzzy-neural network. J Mar Sci Technol, 2009, 17(4), pp. 326-331, doi: 10.6119/JMST .

[5] CLERC M., KENNEDY J. The particle swarm-explosion, stability, and convergence in a multidimensional complex space. IEEE Trans Evol Comput, 2002, 6(1), pp. 58-73, doi: 10. 1109/4235. 985692.

[6] GOH A.T.C. Probabilistic neural network for evaluating seismic liquefaction potential. Can Geotech J, 2002, 39(1), pp. 219-232, doi: 10.1139/t01-073.

[7] GEORGIOU V.L., PAVLIDIS N.G., PAROPOUlOS K.E., ALEVIZOS Ph.D., VRAHATIS M.N. Optimizing the performance of probabilistic neural networks in a bioinformatics task. In: Proceedings of the EUNITE 2004 conference, 2004, pp. 34-40.

[8] GUETTAYA I., OUNI M.R.EL. In situ-based assessment of soil liquefaction potential-case study of an earth dam in Tunisia. Front Struct Civ Eng, 2014, 8(4), pp. 456-461, doi: 10. 1007/s11709-014-0259-5.

[9] JUANG C., YUAN H., LEE D., LIN P. Simplified cone penetration test-based method for evaluating liquefaction resistance of soils. J Geotech Geoenviron Eng, 2003, 129(1), pp. 66-80, doi: 10.1061/(ASCE) 1090-0241(2003) 129:1 (66).

[10] JUANG C.H., CHEN C.J., JIANG T., ANDRUS R.D. Risk-based liquefaction potential evaluation using standard penetration tests. Canad Geotech J, 2000, 37, pp. 1195-1208, doi: $10.1139 / \mathrm{cgj}-37-6-1195$.

[11] JHA S.K., SUZUKI K. Reliability analysis of soil liquefaction based on standard penetration test. Comput Geotech, 2009, 36 (4), pp. 589-596, doi: 10.1016/j. compgeo.2008.10.004.

[12] KENNEDY J., EBERHART R.C. Particle swarm optimization. In Proceedings of the 1995 IEEE International Conference on Neural Networks 4, Perth, Australia. IEEE Service Center: Piscataway, NJ, 1995, pp. 1942-1948.

[13] MARCUSON, W.F., III. Definition of terms related to liquefaction. J Geotech Eng Div $A S C E, 1978,104(9)$, pp. 1197-1200.

[14] MASTERS T. Practical neural network recipes in C++. Academic Press, San Diego, Calif., 1993.

[15] PARZEN E. On estimation of a probability density function and mode. Ann Math Statist, 1962, pp. 33, 1065-1076, doi: 10.1214/aoms/1177704472.

[16] POUR M.N., ASAKEREH A. A comparison between two field methods of evaluation of liquefaction potential in the Bandar Abbas city. Am J Civ Eng, 2015, 3(2-2), pp. 1-5, doi: $10.11648 /$ j.ajce.s.2015030202.11.

[17] PARSOPOULOS K.E. VRAHATIS M.N. Recent approaches to global optimization problems through particle swarm optimization. Nat Comput, 2002, 1(2), pp. 235-306, doi: 10.1023/A : 1016568309421.

[18] SAMUI P., KARTHIKEYAN J. Determination of liquefaction susceptibility of soil: a least square support vector machines approach. Int $J$ Geotech Environ, 2011, 3(1), pp. 75-84, doi: 10.1002/nag. 2081.

[19] SAMUI P., SITHARAM T.G. Machine learning modelling for predicting soil liquefaction susceptibility. Nat Hazards Earth Syst Sci, 2011, 11(1), pp. 1-9, doi: 10.5194/nhess-11-1-2011.

[20] SAMUI P. Liquefaction prediction using support vector machine model based on cone penetration data. Front Struct Civ Eng, 2013, 7(1), pp. 72-82, doi: 10.1007/s11709-013-0185-y. 
Xue X., Yang X., Li P.: Application of a probabilistic neural...

[21] SU Y.H., MA N., HU J., YANG X.L. Estimation of sand liquefaction based on support vector machines. J Cent South Univ Technol, 2008, 15(s2), pp. 15-20, doi: 10.1007/ s11771-008-0429-5.

[22] SPECHT D.F. Probabilistic neural networks. Neural Networks, 1990, 3(1), pp. 109-118, doi: 10.1016/0893-6080 (90) 90049-Q.

[23] SPECHT D.F., ROMSDAHL H. Experience with adaptive probabilistic neural network and adaptive general regression neural network. In Proceedings of the IEEE International Conference on Neural Network, 1994, 2, pp. 1203-1208.

[24] TRELEA I.C. The particle swarm optimization algorithm: Convergence analysis and parameter selection. Inform Process Lett, 2003, 85, pp. 317-325, doi: 10.1016/S0020-0190(02) 00447-7.

[25] XU H.B., CHEN G.H. An intelligent fault identification method of rolling bearings based on LSSVM optimized by improved PSO. Mech Syst Signal Pr, 2013, 35, pp. 167-175, doi: 10. 1016/j.ymssp. 2012.09.005.

[26] YILMAZ A.E., KUZUOGLU M. A particle swarm optimization approach for hexahedral mesh smoothing. Int J Numer Meth Fluids, 2009, 60(1), pp. 55-78, doi: 10.1002/fld.1878.

[27] ZHANG G., ROBERTSON P.K., BRACHMAN R.W.I. Estimating liquefaction-induced lateral displacements using the standard penetration test or cone penetration test. $J$ Geotech Geoenviron Eng, 2004, 130(8), pp. 861-871, doi: 10.1061/(ASCE)1090-0241(2004)130: $8(861)$. 